\title{
5-aminolevulinic acid-incorporated poly(vinyl alcohol) nanofiber-coated metal stent for application in photodynamic therapy
}

This article was published in the following Dove Press journal:

International Journal of Nanomedicine

18 April 2012

Number of times this article has been viewed

\author{
Jin Ju Yoo* \\ Chan Kim* \\ Chung-Wook Chung \\ Young-II Jeong \\ Dae Hwan Kang
}

National Research and Development Center for Hepatobiliary Diseases, Pusan National University Yangsan Hospital, Gyeongnam 626-770, Korea

*These authors contributed equally to this work.
Correspondence: Dae Hwan Kang; Young-II Jeong National Research and Development Center for Hepatobiliary Diseases, Pusan National University Yangsan Hospital, Mulgeum-eup, Yangsan, Gyeongnam 626-770, Republic of Korea

Tel +82 553603870

Fax +82 553603879

Email sulsulpul@yahoo.co.kr; nanomed@naver.com
Background: The study investigated the use of combined photodynamic therapy (PDT) and stent placement for the treatment of cholangiocarcinoma (CC). For this purpose, 5-aminolevulinic acid (ALA) was incorporated into poly(vinyl alcohol) (PVA) nanofiber, and coated onto metal stents. Their efficacy was assessed in PDT towards HuCC-T1 CC cells.

Methods: Fabrication of ALA-PVA nanofiber, and simultaneous coating onto metal stents, was performed through electrospinning. The dark-toxicity, generation of protoporphyrin IX (PpIX), and PDT effect of ALA and ALA-PVA nanofiber were studied in vitro, using HuCC-T1 CC cells.

Results: The ALA-PVA nanofibers were coated onto metal stents less than $1000 \mathrm{~nm}$ in diameter. ALA-only displayed marginal cytotoxicity; ALA-PVA nanofiber showed less cytotoxicity. PpIX generation was not sigficantly different between ALA and ALA-PVA nanofiber treatments. PVA itself did not generate PpIX in tumor cells. ALA and ALA-PVA nanofiber displayed a similar PDT effect on tumor cells. Cell viability was decreased, dose-dependently, until ALA concentration reached $100 \mu \mathrm{g} / \mathrm{mL}$. Necrosis and apoptosis of tumor cells occurred similarly for ALA and ALA- PVA nanofiber treatments.

Conclusion: The ALA-PVA nanofiber-coated stent is a promising candidate for therapeutic use with cholangiocarcinoma.

Keywords: nanofiber, photodynamic therapy, 5-aminolevulinic acid, poly(vinyl alcohol)

\section{Introduction}

Cholangiocarcinoma (CC) is a malignant tumor that arises from epitheial cells of the biliary tree. ${ }^{1}$ Prognosis for CC is generally poor, with a 5-year survival rate of less than $5 \% .^{2}$ In the absence of curative treatment, the median survival of advanced CC patients is less than 24 months. ${ }^{2-4}$ Surgical removal of advanced stage $\mathrm{CC}$ is practically impossible. Palliative therapies, such as endoscopic stent placement, chemotherapy, radiation therapy, and photodynamic therapy (PDT) have been assessed as methods for prolonging survival..$^{5-7}$

PDT incorporates a photosensitizer, light source, and oxygen. Individually, the components are nontoxic. The activated (irradiated) form of the photosensitizer is toxic at the site of action. ${ }^{8,9}$ Among various photosensitizers, 5-aminolevulinic acid (ALA), is a precursor of a strong photosensitizing agent, protoporphyrin IX (PpIX). ALA has been used extensively in clinical applications, due to its safety, feasibility as an effective endogenous photosensitizer for fluorescence diagnosis, and its efficacy in PDT. ${ }^{9-12}$ Photosensitizing agents, administered systemically or locally, accumulate mainly in tumor cells. The agent is activated, using light of a specific wavelength, to 
induce a photochemical inhibitory effect upon cancer cells that contain the activated compound.

Nanoscale materials and devices, such as nanoparticles, nanofibers, and nanodevices represent a new class of biomedical materials, which have unique biochemical and physiological properties. ${ }^{13-16}$ Polymer nanofibers, especially, have been investigated extensively for biomedical applications in recent decades. ${ }^{15,17,18}$ Because they are of similar scale to biological structures and systems, nanofibers are able to mimic the biological microenvironment and stimulate the therapeutic potential of medical agents.

In this study, we explored the novel concept of combining metal stent placement and ALA-based PDT as a therapy for CC. ALA was incorporated into poly(vinyl alcohol) (PVA) nanofibers (ALA-PVA) and coated onto metal stents. In this preliminary study, the PDT effect of this nanofiber was investigated in vitro using CC cells.

\section{Methods and materials Materials}

PVA (13,000-23,000 g/M; 87\%-89\% hydrolyzed), ALA, 2',3-[4,5-dimethylthiazol-2-yl]-2,5-diphenyltetrazolium bromide (MTT), and 4-(2-hydroxyethyl)-1-piperazineethanesulfonic acid (HEPES) were purchased from Sigma-Aldrich (St Louis, MO). Cell culture materials were purchased from Invitrogen (Carlsbad, CA). Propidium iodide (PI) and fluorescein isthiocynate (FITC)-annexin $\mathrm{V}$ were obtained from BD Biosciences (Sparks, MD).

\section{Metal stent coated with PVA nanofiber}

To prepare the nanofiber-coated stents, $1350 \mathrm{mg}$ of PVA and $150 \mathrm{mg}$ of ALA were completely dissolved in $10 \mathrm{~mL}$ of water. This solution was transferred into a spin pack containing spinnerets. Electrospinning was carried out using typical apparatus (Amotech, Kimpo, Korea). A voltage of $25 \mathrm{kV}$ was applied to the polymer solution via the spinneret tip (Figure 1A). ${ }^{19}$ PVA solutions containing ALA were sprayed onto a rolling collector (diameter: $1 \mathrm{~cm}$; length: $10 \mathrm{~cm}$; rolling speed: $800 \mathrm{rpm}$ ) at a rate of $50 \mu \mathrm{L}$ per minute. PVA nanofiber-coated stents were dried for 3 hours in darkness, with reduced pressure. The nanofiber-coated stents were then carefully isolated from the collector and weighed. For studying PDT, ALA- PVA nanofiber was suspended in phosphate-buffered saline (PBS) $(0.01 \mathrm{M}$, $\mathrm{pH} 7.4$ ), then sterilized using a $0.2 \mu \mathrm{m}$ syringe filter.

\section{Cell culture}

The HuCC-T1 human intrahepatic CC cell line was obtained from Health Science Research Resources Bank (Osaka,
Japan). The cells were cultured in RPMI1640, containg 10\% fetal bovine serum (FBS) and 1\% penicillin/streptomycin, buffered with $25 \mathrm{mM}$ HEPES in an incubator operated at at $37^{\circ} \mathrm{C}$ with $5 \% \mathrm{CO}_{2}$ concentration.

\section{PpIX accumulation assay}

HuCC-T1 cells $\left(1 \times 10^{6}\right)$ were seeded in 6-well plates and treated with ALA for 24 hours in serum-free medium, washed with PBS, then lysed with cell lysis buffer (GenDEPOT, Barker, TX). PpIX accumulation in cells was measured using an Infinite ${ }^{\circledR}$ M200 PRO microplate reader (Tecan, Männedorf, Switzerland), at excitation and emission wavelengths of $485 \mathrm{~nm}$ and $635 \mathrm{~nm}$, respectively.

\section{Dark toxicity}

HuCC-T1 cells were seeded in wells of a 96-well plate $\left(1 \times 10^{4}\right.$ cells/well $)$ with $100 \mu \mathrm{L}$ of culture medium. Cells were incubated in a $\mathrm{CO}_{2}$ incubator at $37^{\circ} \mathrm{C}$ for 24 hours. Cells were then treated with various concentrations of ALA, or ALA-PVA nanofiber, in serum-free medium for 24 hours. The medium was changed to a growth medium, containing $10 \% \mathrm{FBS}$, and incubated for 24 hours. Cell viability was measured by MTT assay, as reported previously. ${ }^{20} 25 \mu \mathrm{L}$ of MTT ( $3 \mathrm{mg} / \mathrm{mL}$ in PBS) was added to each well, and cells were then incubated for an additional 4 hours. Subsequently, $100 \mu \mathrm{L}$ of sodium dodecyl sulfate $(10 \% \mathrm{w} / \mathrm{v})$ - hydrochloric acid $(0.01 \mathrm{M})$ solution was added to each well, and cells were incubated for an additional 12 hours at $37^{\circ} \mathrm{C}$ with $5 \%$ $\mathrm{CO}_{2}$. Next, absorbance was measured at a wavelength of $570 \mathrm{~nm}$ using the Infinite ${ }^{\circledR} \mathrm{M} 200 \mathrm{PRO}$ reader. All experiments were conducted in triplicate. Cell viability was expressed in percentages against controls. Results were calculated as means with standard deviations for three different experiments.

\section{Light sources for PDT}

Cultured cell plates were exposed to light-emitting diode irradiation lamps (SH System, Gwangju, Korea), at $635 \mathrm{~nm}$ wavelength. Light intensity was $0.25 \mathrm{~J} / \mathrm{cm}^{2}$, as measured by a photo radiometer (Delta Ohm, Padua, Italy).

\section{Cell viability assay}

HuCC-T1 cells were treated with various concentrations of ALA or ALA-PVA nanofiber in serum-free medium for 24 hours. Cells were then irradiated with $0.25 \mathrm{~J} / \mathrm{cm}^{2}$ at $635 \mathrm{~nm}$ wavelength. The medium was changed, and cell viability was assessed by MTT assay. 


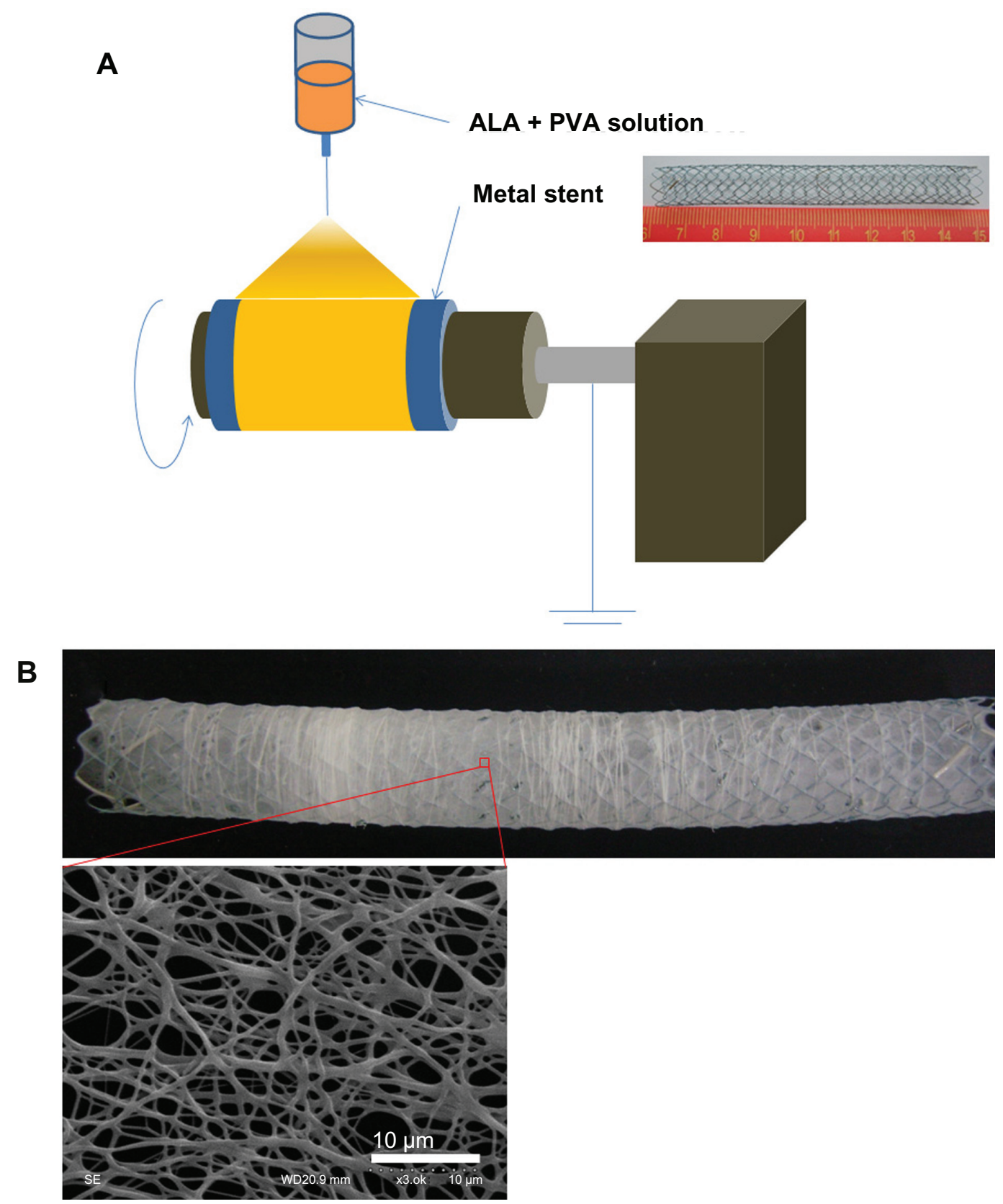

Figure I (A) Schematic illustration of ALA-PVA nanofiber coated onto metal stent; (B) field emission-scanning electron microscopy image. Abbreviations: ALA, 5-aminolevulinic acid; PVA, poly(vinyl alcohol).

\section{Flow cytometry}

Apoptosis and necrosis of HuCC-T1 cells were analyzed by flow cytomwtry. ${ }^{7}$ FITC annexin V and PI were employed to analyze apoptosis and necrosis of HuCC-T1 cells, respectively. Cells were exposed to ALA for 24 hours, then irradiated with $0.25 \mathrm{~J} / \mathrm{cm}^{2}$ at $635 \mathrm{~nm}$ wavelength. Cells were harvested and washed with PBS. Cell pellets were then resuspended in a binding buffer $(\mathrm{pH} 7.4 ; 10 \mathrm{mM}$ HEPES, $150 \mathrm{mM} \mathrm{NaCl}, 5 \mathrm{mM} \mathrm{KCl}, 1 \mathrm{mM} \mathrm{MgCl} 2,1.8 \mathrm{mM} \mathrm{CaCl}_{2}$ ), containing FITC annexin $\mathrm{V}(1 \mu \mathrm{g} / \mathrm{mL})$, then further incubated for 30 minutes. Ten minutes prior to the termination of incubation, PI $(10 \mu \mathrm{g} / \mathrm{mL})$ was added, to stain necrotic cells under dark conditions. Cells were analyzed immediately, using a FACScan ${ }^{\mathrm{TM}}$ flow cytometer (Becton Dickinson Biosciences, San Jose, CA).

\section{Fluorescence microscopy}

Accumulation of PpIX was observed using an Eclipse 80i fluorescence microscope (Nikon, Tokyo, Japan). PpIX was detected using a 460-480 nm excitation filter and $610 \mathrm{~nm}$ 
emission filter. Cells were seeded onto cover glasses, positioned in a 6 -well plate $\left(1 \times 10^{6} \mathrm{HuCC}\right.$-T1 cells/well $)$, then treated with ALA or ALA-PVA nanofiber for 24 hours in serum-free medium. The medium was discarded, and the cover glasses were washed with PBS. The cells were fixed for 10 minutes in 4\% paraformaldehyde in PBS, and mounted onto glass slides. PpIX generation in tumor cells was observed with fluorescence microscopy.

\section{Results}

\section{Characterization of ALA-incorporated PVA nanofibers}

The porous and fibrous nanomaterial, PVA-ALA, was coated onto metal stents (Figure 1). PVA-ALA nanofibers were properly coated onto the stents (Figure 1B). The diameter of the coated fibrous matter varied, but was always less than $1000 \mathrm{~nm}$. To test its biological activity and phototoxicity, ALA-PVA nanofiber was suspended in PBS.

\section{Dark toxicity}

Before investigating the effect of ALA-PVA nanofiber with PDT, we studied the intrinsic toxicities of ALA and ALAPVA, using HuCC-T1 cells. As shown in Figure 2, various concentrations of ALA and ALA-PVA (drug/polymer ratio: 1/9) were used to treat HuCC-T1 cells for 24 hours, in the absence of irradiation. ALA itself was only marginally toxic; survival exceeded $70 \%$, even at ALA concentrations less than $100 \mu \mathrm{g} / \mathrm{mL}$; ALA-PVA was even less cytotoxic. Interestingly, PVA appeared to reduce the intrinsic toxicity of ALA. $90 \%$ survival of tumor cells was noted in ALA concentrations that exceeded $200 \mu \mathrm{g} / \mathrm{mL}$. These results indicate that PVA, and PVA nanofibers, did not appreciably affect the viability of $\mathrm{HuCC}-\mathrm{T} 1$ cells.

\section{PpIX generation in HuCC-TI cells and phototoxicity}

PpIX generation in HuCC-T1 CC cells treated with ALA or ALA-PVA nanofiber is summarized in Figure 3. The extent of PpIX generation was not significantly different between ALA-only and ALA-PVA nanofiber treatment. PVA itself did not generate PpIX in tumor cells. Interestingly, at ALA concentrations greater than $50 \mu \mathrm{g} / \mathrm{mL}$, PpIX generation, under treatment with ALA-PVA nanofiber, was slightly greater than for ALA only. PpIX generation in HuCC-T1 cells was confimed by fluorescence microscopy (Figure 4), which indicated that ALA-PVA nanofiber produced PpIX in tumor cells as avidly as did ALA alone. Figure 5 summarizes data concerning the phototoxicity of ALA and ALA-PVA nanofiber towards HuCC-T1 cells. Tumor cells were irradiated 24 hours after treatment with ALA or ALA-PVA nanofiber.

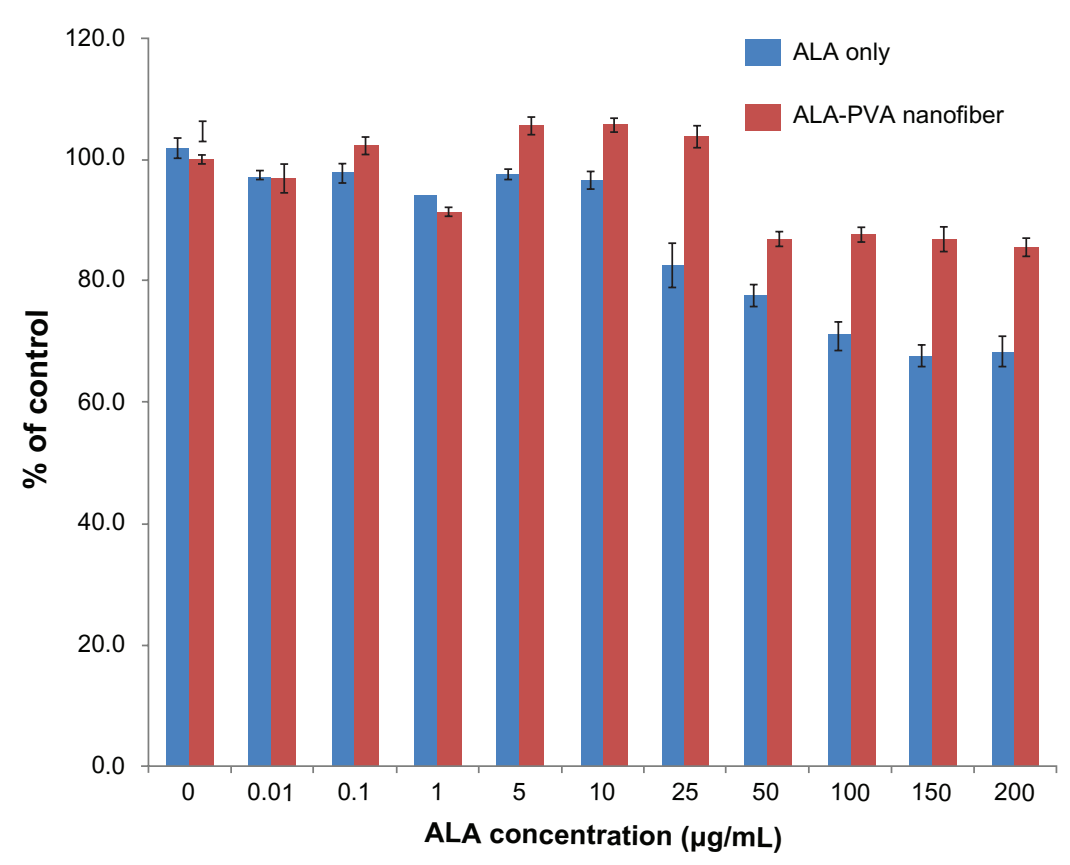

Figure 2 Dark toxicity of ALA-only and ALA-PVA nanofiber against HuCC-TI cholangiocarcinoma cells.

Notes: ALA, dissolved in dimethylsulfoxide, was diluted with serum-free media at least 100 times, then used in treating HuCC-TI cells. For ALA-PVA, a calculated amount of nanofiber (ALA/PVA ratio: I/9, w/w), from metal stents suspended in serum-free medium, was sterilized using a syringe filter (pore size: $0.2 \mu \mathrm{m}$ ). The preparation was used to treat tumor cells.

Abbreviations: ALA, 5-aminolevulinic acid; PVA, poly(vinyl alcohol). 


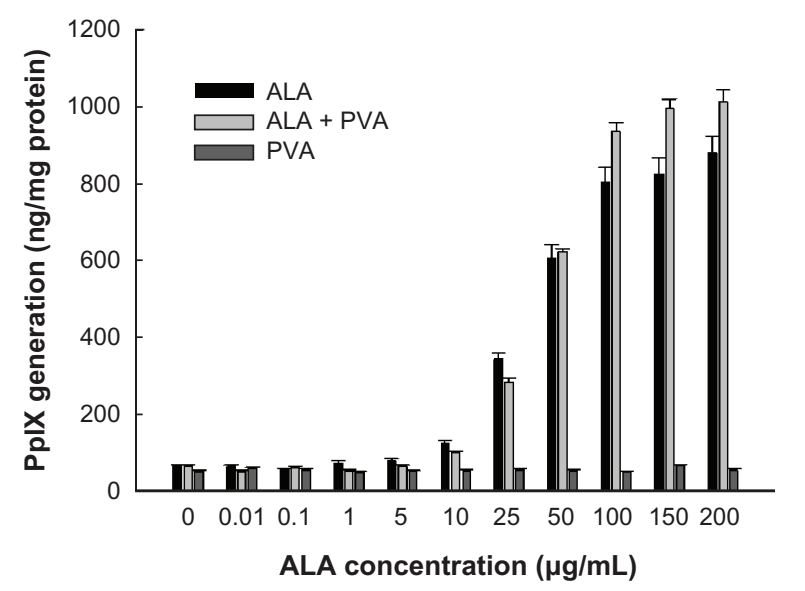

Figure 3 The effect of ALA and ALA-PVA nanofiber on PpIX generation in HuCC-TI CC cells.

Notes: ALA dissolved in dimethylsulfoxide was diluted with serum-free media at least 100 times, then used in treating HuCC-TI cells. For ALA-PVA, the procedure detailed in the notes to Figure 2 was followed.

Abbreviations: ALA, 5-aminolevulinic acid; CC, cholangiocarcinoma; PpIX, protoporphyrin IX; PVA, poly(vinyl alcohol).

The decrease in cell viability caused by ALA-PVA nanofiber treatment was very similar to that caused by ALA alone, whereas PVA alone did not induce death in tumor cells (Figure 5). Tumor cell viability decreased dose-dependently until ALA concentration reached $100 \mu \mathrm{g} / \mathrm{mL}$, and remained constant with increased concentration. These results indicate that PpIX was generated in a dose-dependent manner by treatment with ALA or ALA-PVA nanofiber, which induced PDT-mediated cell death.

\section{Apoptosis and necrosis of tumor cells}

To investigate the mechanism of tumor cell death, HuCC-T1 cells, treated with ALA or ALA-PVA nanofiber, were stained with FITC annexin V, to detect apoptotic cells, and with PI, to detect necrotic cells. As shown in Figure 6, the number of necrotic and apoptotic cells gradually increased until an ALA concentration of $25 \mu \mathrm{g} / \mathrm{mL}$ was reached. At $100 \mu \mathrm{g} / \mathrm{mL}$ ALA, the number of necrotic cells significantly increased, while that of apoptotic cells slightly decreased, indicating that these results are a reflection of cell death. Necrosis of tumor cells was dominant at ALA concentrations exceeding $100 \mu \mathrm{g} / \mathrm{mL}$.

\section{Discussion}

$\mathrm{CC}$ is an incurable adenocarcinoma, arising from cholangiocytes. Even though operative removal would offer the greatest hope for a cure, this option is impossible. Palliative therapeutic
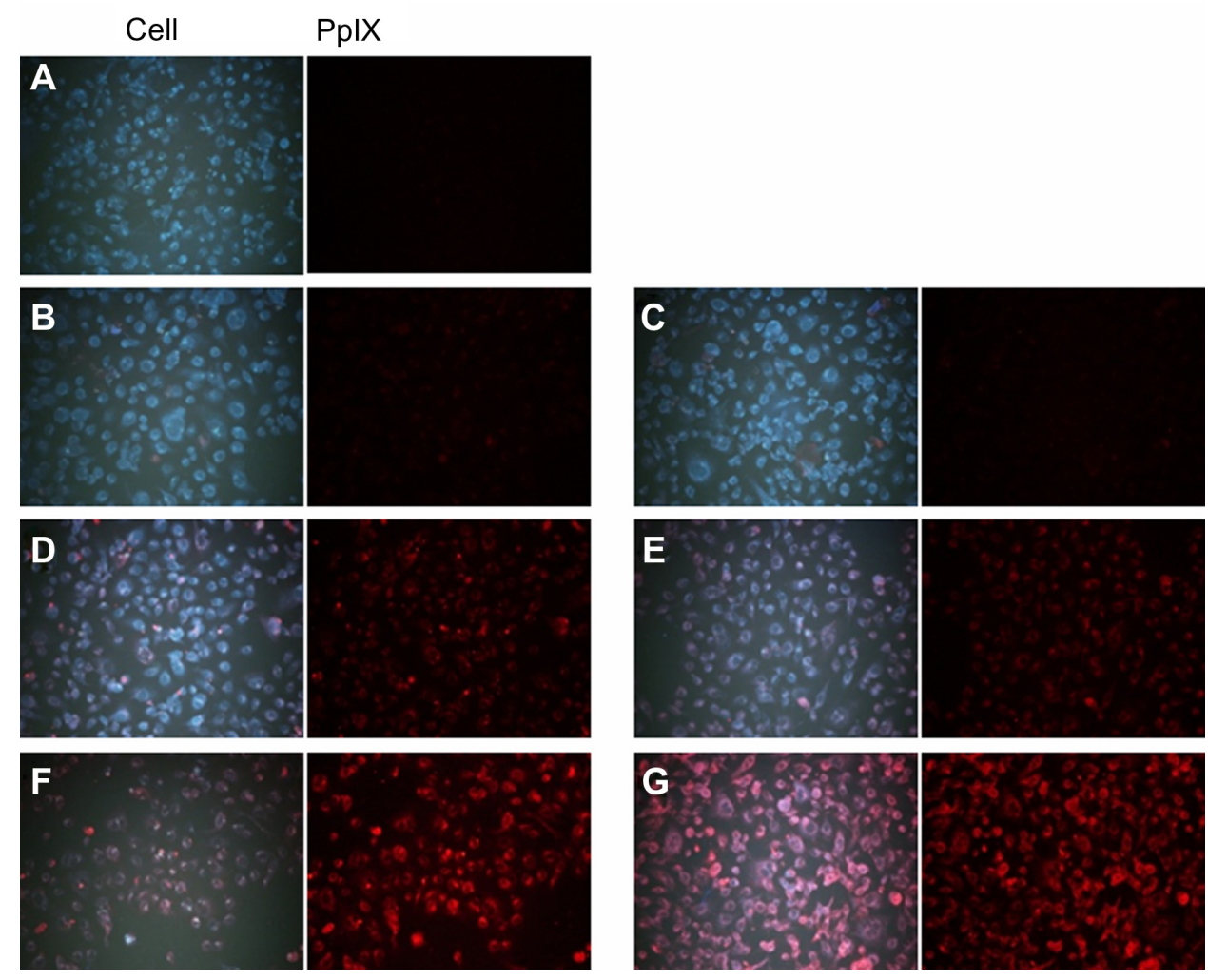

Figure 4 Fluorescence images of HuCC-TI cholangiocarcinoma cells after treatment with ALA and ALA-PVA nanofiber.

Notes: (A) zero ALA; (B) $10 \mu \mathrm{g} / \mathrm{mL}$ ALA; (C) $10 \mu \mathrm{g} / \mathrm{mL}$ ALA-PVA nanofiber; (D) $25 \mu \mathrm{g} / \mathrm{mL}$ ALA; (E) $25 \mu \mathrm{g} / \mathrm{mL}$ ALA-PVA nanofiber; (F) $100 \mu \mathrm{g} / \mathrm{mL}$ ALA; (G) $100 \mu \mathrm{g} / \mathrm{mL}$ ALA-PVA nanofiber.

Abbreviations: ALA, 5-aminolevulinic acid; PpIX, protoporphyrin IX; PVA, poly(vinyl alcohol). 


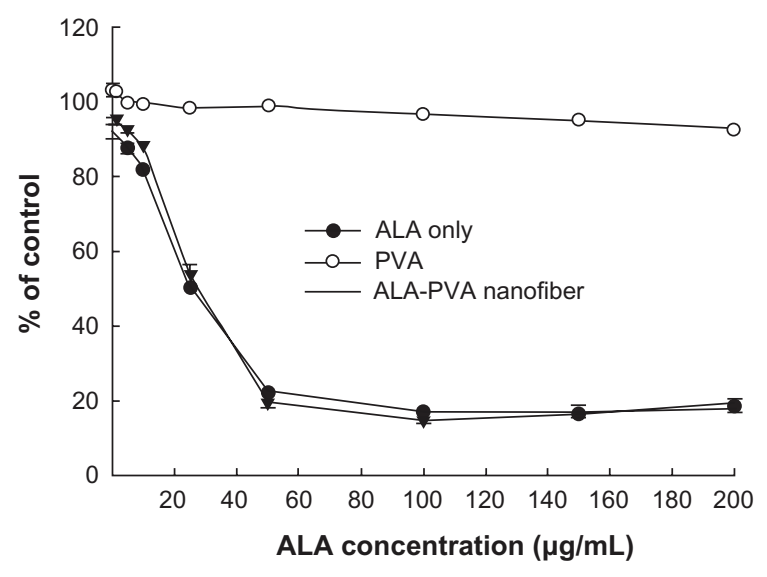

Figure 5 Phototoxicity of ALA and ALA-PVA nanofiber towards HuCC-TI CC cells. Notes: HuCC-TI cells were treated with ALA or ALA-PVA nanofiber in serumfree medium for 24 hours. Cells were then irradiated with $0.25 \mathrm{~J} / \mathrm{cm}^{2}$ at $635 \mathrm{~nm}$ wavelength.

Abbreviations: ALA, 5-aminolevulinic acid; CC, cholangiocarcinoma; PVA, poly(vinyl alcohol).

modalities are generally used, such as radiotherapy, chemotherapy, stent placement, and PDT. Among these modalities, no beneficial effect can be expected from radiotherapy or chemotherapy. ${ }^{6,21-23}$ PDT and metal stent placement are the most promising approaches for prolonging patient life..$^{24,25}$ When a tumor blocks the bile duct, insertion of a metal stent enables bile drainage. An uncoated metal stent offers simple mechanical palliation, without anti-tumor efficacy. ${ }^{26}$ In a recent review, Chahal and Baron ${ }^{25}$ suggested that PDT with stenting could hold promise for managing locally unresectable cholangiocarcinoma, rather than solely as a means for prolongation of life. The advantages of PDT include its safety; minimal side-effects compared to radiotherapy or chemotherapy; and the feasibility of local treatment for gastrointestinal cancer, because nontoxic components - light and a photosensitizing agent - are used for treatment. ${ }^{25,27}$

Nanofiber technology, for drug delivery or biotechnological applications, has been investigated extensively over recent decades. ${ }^{15-17}$ Nanofibers form an ultraporous matrix with superior mechanical properties and high surface area for weight. ${ }^{28,29}$ Various types of polymeric materials can be used to make them..$^{28,29}$ Nanofibers fabricated with PVA and poly(N-isopropylacrylamide) are known to be effective vehicles for enhanced topical delivery of drugs. ${ }^{30}$ The nanofibrous membrane of PVA has previously been used to maintain the stability and biological activity of (-)-epigallocatechin-3-gallate (EGCG). ${ }^{31}$ The cellular response of PVA nanofibers containing silver nanoparticles has also been investigated. ${ }^{32}$

We prepared ALA-PVA nanofiber-coated metal stents using the electrospinning method (Figure 1).
PVA, which is a water-soluble surfactant, can be used as a vehicle for ALA, because ALA is a small, water-soluble molecule, insoluble in organic solvents. Since ALA is labile and light sensitive, PVA nanofiber could help to maintain its stability and biological activity.

ALA-PVA nanofiber was coated onto the metal stent - not uniformly. PVA nanofiber itself did not affect the viability of tumor cells (Figure 2). Since PpIX generation was slightly increased at high ALA concentration (Figures 3 and 4), ALA-PVA nanofiber coating of metal stents is a promising method for delivery of ALA to tumor cells. We previously reported that nonionic surfactants, such as Pluronic ${ }^{\circledR}$ F68 or Tween ${ }^{\circledR} 80$ (Sigma-Aldrich), effectively enhance ALA uptake by tumor cells. ${ }^{33}$ We suggest that PVA nanofibers are also effective vehicles for delivery of ALA.

The present study combined PDT with stent placement, for palliative therapy for CC (Figure 7). Cheon et al reported that PDT with stenting resulted in longer survival than stenting alone. ${ }^{34}$ They observed longer survivability in patients after PDT treatment and subsequent placement of a metal stent. Local administration of a photosensitizer, combined with a metal stent, can be considered a more feasible treatment option than that of systemic administration, in the case of bile duct cancer, because local treatment provides better accumulation and more favorable biodistribution of photosensitizer in tumor tissue, leading to selective tumor cell death. ${ }^{35}$ We prepared ALA-PVA nanofiber to coat metal stents (Figure 1). As far as we know, this is the first use of this suggestion for palliative therapy for unresectable CC; it was suggested that PDT and stent placement offer hope for such treatment. ${ }^{22-26}$ As shown in Figure 7, combined treatment, with PDT and ALA-PVA nanofiber-coated metal stent, involved only two steps. In the first step, the nanofiber-coated stent is placed in the bile duct compromised by CC. At this stage, PpIX is generated after uptake of ALA by tumor cells. In the second step, irradiation is perfomed. PDT inhibits the growth or spread of the tumor. For this purpose, we selected ALA as a photosensitizing agent, because ALA is less cytotoxic towards normal cells in the absence of irradiation, compared with other photosensiting agents. Furthermore, PpIX accumulation in ALA-treated tumor cells is greater than in normal cells. ${ }^{7}$ In general, the method for PDT treatment is a two-step process, involving (1) accumulation of the photosensitizing agent in tumor cells, and (2) subsequent lethal activation of the agent by irradiation at a specific wavelength. ${ }^{7}$ Irradiation induces an injurious photochemical reaction, in which the activated agent transfers energy to molecular oxygen, generating reactive oxygen species, ${ }^{7}$ which oxidize lipids, amino acids, 


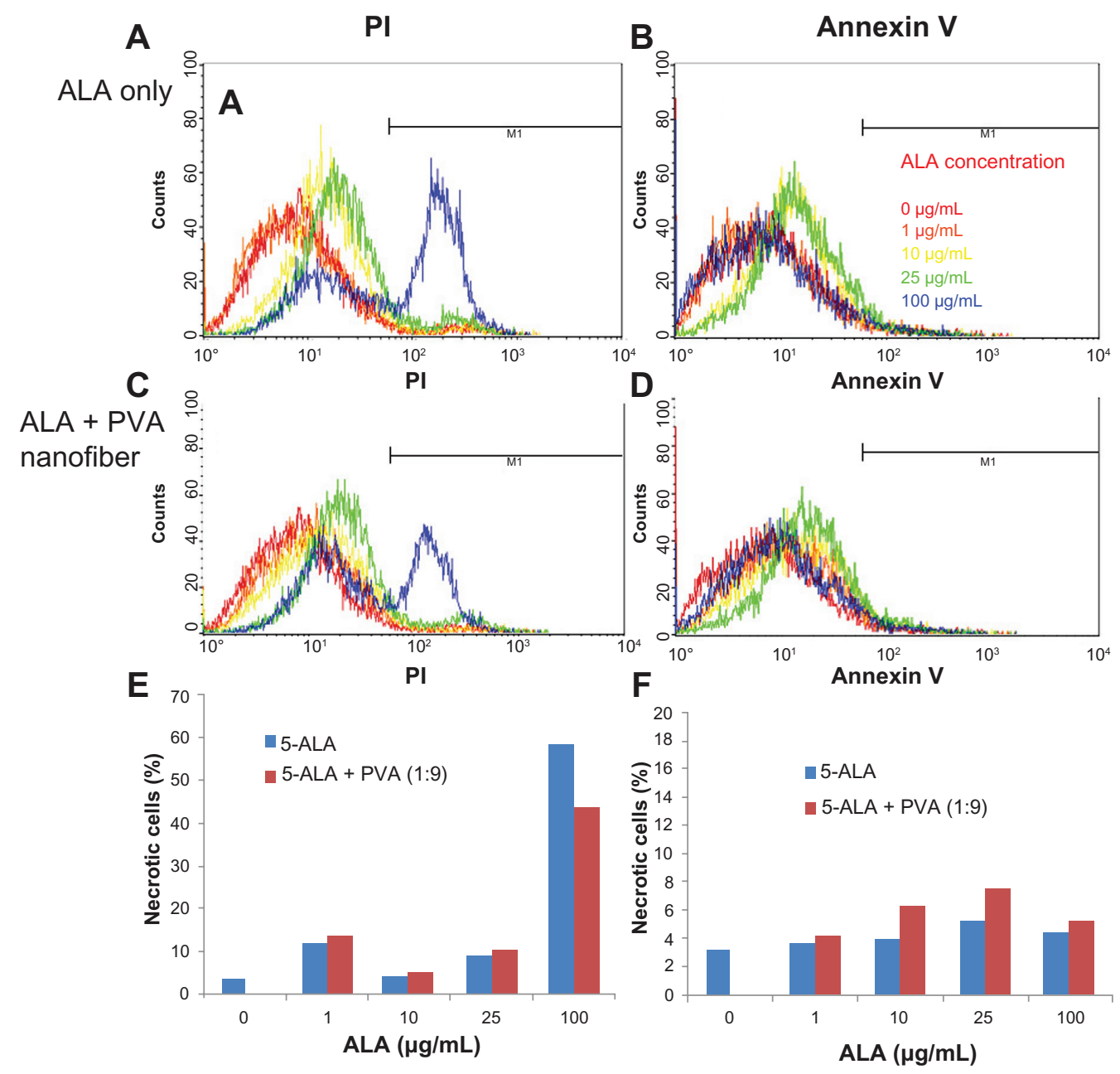

Figure 6 Apoptosis and necrosis analysis of HuCC-TI cholangiocarcinoma cells, after treatment with ALA-only or ALA-PVA nanofiber for 24 hours. Notes: Cells were stained with PI for necrosis and FITC annexin V for apoptosis: (A and B) ALA only; (C and D) ALA-PVA nanofiber. The percentage of MI area of total cells is displayed in graph form for $(\mathbf{E})$ necrosis and $(\mathbf{F})$ apoptosis.

Abbreviations: ALA, 5-aminolevulinic acid; PVA, poly(vinyl alcohol); PI, propidium iodide; FITC, fluorescein isthiocynate.

\section{Cholangiocarcinoma}
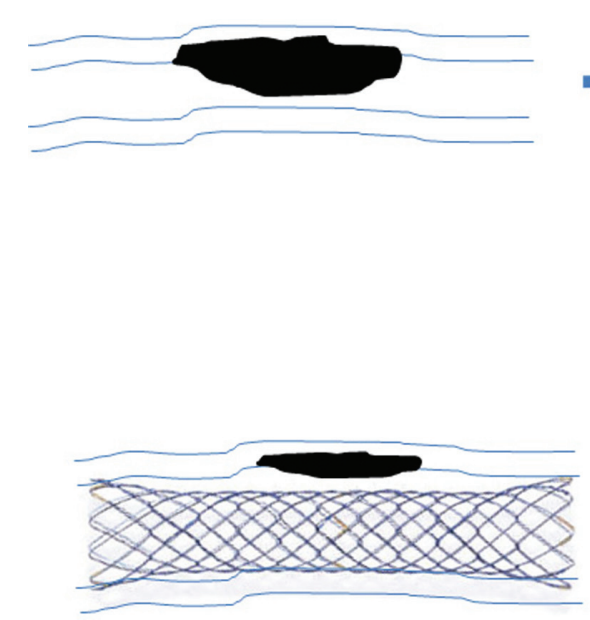

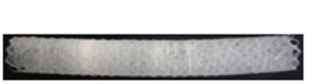

Operation of ALA-incorporated

PVA nanofiber coated metal stent

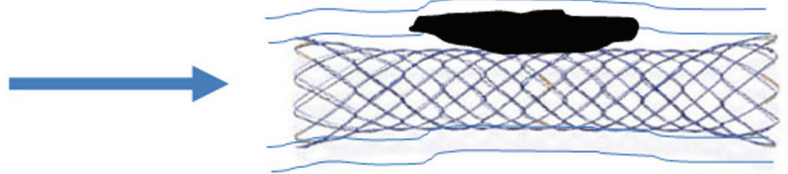

ALA-incorporated PVA nanofiber immediately dissolved

\section{Light irradiation}

Figure 7 Schematic illustration of combination of stent placement and PDT for cholangiocarcinoma. Abbreviations: PDT, photodynamic therapy; ALA, 5-aminolevulinic acid; PVA, poly(vinyl alcohol). 
and proteins, inducing necrosis and apoptosis. As shown in Figure 5, ALA-PVA nanofiber maintained a PDT effect similar to that of ALA alone. In the absence of irradiation, reduced cytotoxicity was observed with ALA-PVA nanofiber (Figure 2). PpIX generation increased with greater ALA concentration. PVA itself did not influence the interconversion between ALA and PpIX (Figures 3 and 4). Even though the extent of apoptosis and necrosis changed slightly, ALA-PVA nanofiber treatment showed a similar cell death mechanism to ALA alone, in the apoptosis and necrosis analyses (Figure 6). Necrosis predominated at ALA concentrations greater than $100 \mu \mathrm{g} / \mathrm{mL}$. Apoptosis resulting from treatment with ALAPVA nanofiber was slightly greater than that resulting from ALA alone. These results indicate that that ALA-PVA nanofiber has anti-tumor activity, and can generate a PDT effect on HuCC-T1 CC cells.

\section{Conclusion}

ALA-PVA nanofiber was coated onto metal stents for combined PDT and stent placement for palliative therapy of unresectable CC. ALA-PVA nanofiber maintained activity similar to ALA alone in generation of PpIX, contributing to cell death, while it was less cytotoxic in the absence of irradiation. ALA-PVA nanofiber-coated stents offer promise in therapy for $\mathrm{CC}$.

\section{Disclosure}

The authors report no conflicts of interest in this work.

\section{Acknowledgment}

This study was supported by a grant from the Korea Healthcare Technology R and D Project, Ministry of Health and Welfare, Republic of Korea (Project No A091047).

\section{References}

1. Ustundag Y, Bayraktar Y. Cholangiocarcinoma: a compact review of the literature. World J Gastroenterol. 2008;14(42):6458-6466.

2. Shaib YH, Davila JA, McGlynn K, El-Serag HB. Rising incidence of intrahepatic cholangiocarcinoma in the United States: a true increase? J Hepatol. 2004;40(3):472-477.

3. Lazaridis KN, Gores GJ. Cholangiocarcinoma. Gastroenterology. 2005;128(6):1655-1667.

4. Mosconi S, Beretta GD, Labianca R, Zampino MG, Gatta G, Heinemann V. Cholangiocarcinoma. Crit Rev Oncol Hematol. 2009;69(3):259-270.

5. Lee JH, Kang DH, Kim JY, et al. Endoscopic bilateral metal stent placement for advanced hilar cholangiocarcinoma: a pilot study of a newly designed Y stent. Gastrointest Endosc. 2007;66(2):364-369.

6. Brunner TB, Eccles CL. Radiotherapy and chemotherapy as therapeutic strategies in extrahepatic biliary duct carcinoma. Strahlenther Onkol. 2010;186(12):672-680.

7. Kim $\mathrm{CH}$, Chung $\mathrm{CW}$, Choi $\mathrm{KH}$, et al. Effect of 5-aminolevulinic acidbased photodynamic therapy via reactive oxygen species in human cholangiocarcinoma cells. Int J Nanomedicine. 2011;6:1357-1363.
8. Issa MC, Manela-Azulay M. Photodynamic therapy: a review of the literature and image documentation. An Bras Dermatol. 2010;85(4): 501-511.

9. Nishioka NS. Drug, light, and oxygen: a dynamic combination in the clinic. Gastroenterology. 1998;114(3):604-606.

10. Richter JA, Kahaleh M. Photodynamic therapy: Palliation and endoscopic technique in cholangiocarcinoma. World J Gastrointest Endosc. 2010;2(11):357-361.

11. Taylor EL, Brown SB. The advantages of aminolevulinic acid photodynamic therapy in dermatology. $J$ Dermatolog Treat. 2002;13 Suppl 1:S3-S11.

12. Calzavara-Pinton PG, Venturini M, Sala R. Photodynamic therapy: update 2006. Part 1: Photochemistry and photobiology. J Eur Acad Dermatol Venereol. 2007;21(3):293-302.

13. Choi HS, Frangioni JV. Nanoparticles for biomedical imaging: fundamentals of clinical translation. Mol Imaging. 2010;9(6): 291-310.

14. Jeong YI, Kim do H, Chung CW, et al. Doxorubicin-incorporated polymeric micelles composed of dextran-b-poly(DL-lactide-coglycolide) copolymer. Int J Nanomedicine. 2011;6:1415-1427.

15. Gunn J, Zhang M. Polyblend nanofibers for biomedical applications: perspectives and challenges. Trends Biotechnol. 2010;28(4):189-197.

16. Leucuta SE. Nanotechnology for delivery of drugs and biomedical applications. Curr Clin Pharmacol. 2010;5(4):257-280.

17. Vasita R, Katti DS. Nanofibers and their applications in tissue engineering. Int J Nanomedicine. 2006;1(1):15-30.

18. Guo G, Fu S, Zhou L, Liang H, et al. Preparation of curcumin loaded poly( $\varepsilon$-caprolactone)-poly(ethylene glycol)-poly( $\varepsilon$-caprolactone) nanofibers and their in vitro antitumor activity against Glioma 9L cells. Nanoscale. 2011;3(9):3825-3832.

19. Cho E, Kim C, Kook JK, et al. Fabrication of electrospun PVDF nanofiber membrane for Western blot with high sensitivity. J Memb Sci. 2012;389:349-354.

20. Chung KD, Jeong YI, Chung CW, Kim DH, Kang DH. Anti-tumor activity of all-trans retinoic acid-incorporated glycol chitosan nanoparticles against HuCC-T1 human cholangiocarcinoma cells. Int J Pharm. 2012;422:454-461.

21. Cendan JC, Zlotecki RA, Vauthey JN. Biliary tract cancer. Curr Opin Gastroenterol. 1996;12(5):460-465.

22. Wijaya I, Abdullah M. Diagnosis and treatment update: cholangiocarcinoma. Acta Med Indones. 2011;43(3):212-215.

23. Mantel HT, Verdonk RC, van Dullemen HM, Gietema JA, Slooff MJ, Porte RJ. Diagnostics and treatment of cholangiocarcinoma. Ned Tijdschr Geneeskd. 2008;152(18):1037-1041.

24. Singh $P$, Patel T. Advances in the diagnosis, evaluation and management of cholangiocarcinoma. Curr Opin Gastroenterol. 2006;22(3): 294-299.

25. Chahal P, Baron TH. Endoscopic palliation of cholangiocarcinoma. Curr Opin Gastroenterol. 2006;22(5):551-560.

26. Lee DH. Drug-eluting stent in gastrointestinal disease. Korean J Gastroenterol. 2007;49:294-299.

27. Gao F, Bai Y, Ma SR, Liu F, Li ZS. Systematic review: photodynamic therapy for unresectable cholangiocarcinoma. J Hepatobiliary Pancreat Sci. 2010;17(2):125-131.

28. Kriegel C, Arecchi A, Kit K, McClements DJ, Weiss J. Fabrication, functionalization, and application of electrospun biopolymer nanofibers. Crit Rev Food Sci Nutr. 2008;48(8):775-797.

29. Venugopal J, Ramakrishna S. Applications of polymer nanofibers in biomedicine and biotechnology. Appl Biochem Biotechnol. 2005;125(3): $147-158$.

30. Azarbayjani AF, Venugopal JR, Ramakrishna S, Lim PF, Chan YW, Chan SY. Smart polymeric nanofibers for topical delivery of levothyroxine. J Pharm Sci. 2010;13(3):400-410.

31. Sun LM, Zhang CL, Li P. Characterization, antimicrobial activity, and mechanism of a high-performance (-)-epigallocatechin-3-gallate (EGCG)-CuII/polyvinyl alcohol (PVA) nanofibrous membrane. J Agric Food Chem. 2011;59(9):5087-5092. 
32. Chun JY, Kang HK, Jeong L, et al. Epidermal cellular response to poly(vinyl alcohol) nanofibers containing silver nanoparticles. Colloids Surf B Biointerfaces. 2010;78(2):334-342.

33. Chung CW, Kim CH, Choi KH, etal. Effect of surfactant on 5-aminolevulinic acid uptake and PpIX generation in human cholangiocarcinoma cell. Eur J Pharm Biopharm. 2012;80(2):453-458.
34. Cheon YK, Lee TY, Lee SM, Yoon JY, Shim CS. Longterm outcome of photodynamic therapy compared with biliary stenting alone in patients with advanced hilar cholangiocarcinoma. HPB (Oxford). 2012;14(3):185-193.

35. Tomizawa Y, Tian J. Photodynamic therapy for unresectable cholangiocarcinoma. Dig Dis Sci. 2012;57(2):274-283.
International Journal of Nanomedicine

\section{Publish your work in this journal}

The International Journal of Nanomedicine is an international, peerreviewed journal focusing on the application of nanotechnology in diagnostics, therapeutics, and drug delivery systems throughou the biomedical field. This journal is indexed on PubMed Central, MedLine, CAS, SciSearch $®$, Current Contents $® /$ Clinical Medicine,

\section{Dovepress}

Journal Citation Reports/Science Edition, EMBase, Scopus and the Elsevier Bibliographic databases. The manuscript management system is completely online and includes a very quick and fair peer-review system, which is all easy to use. Visit http://www.dovepress.com/ testimonials.php to read real quotes from published authors.

Submit your manuscript here: http://www.dovepress.com/international-journal-of-nanomedicine-journal 